\title{
Impact of Soil Moisture Data Resolution on Soil Moisture and Surface Heat Flux Estimates through Data Assimilation: A Case Study in the Southern Great Plains
}

\author{
YANG LU \\ Department of Water Management, Faculty of Civil Engineering and Geosciences, \\ Delft University of Technology, Delft, Netherlands \\ JIANZHI DONG \\ Hydrology and Remote Sensing Laboratory, USDA, Beltsville, Maryland \\ SUSAN C. STEELE-DUNNE \\ Department of Water Management, Faculty of Civil Engineering and Geosciences, \\ Delft University of Technology, Delft, Netherlands
}

(Manuscript received 31 October 2018, in final form 4 February 2019)

\begin{abstract}
The spatial heterogeneity and temporal variation of soil moisture and surface heat fluxes are key to many geophysical and environmental studies. It has been demonstrated that they can be mapped by assimilating soil thermal and wetness information into surface energy balance models. The aim of this work is to determine whether enhancing the spatial resolution or temporal sampling frequency of soil moisture data could improve soil moisture or surface heat flux estimates. Two experiments are conducted in an area mainly covered by grassland, and land surface temperature (LST) observations from the Geostationary Operational Environmental Satellite (GOES) mission are assimilated together with either an enhanced L-band passive soil moisture product ( $9 \mathrm{~km}, 2-3$ days) from the Soil Moisture Active Passive (SMAP) mission or a merged product (36 km, quasi-daily) from the SMAP and the Soil Moisture Ocean Salinity (SMOS) mission. The results suggest that the availability of soil moisture observations is increased by $41 \%$ after merging data from the SMAP and the SMOS missions. A comparison with results from a previous study that assimilated a coarser SMAP soil moisture product $(36 \mathrm{~km}, 2-3$ days) suggests that enhancing the temporal sampling frequency of soil moisture observations leads to improved soil moisture estimates at both the surface and root zone, and the largest improvement is seen in the bias metric $\left(0.008\right.$ and $0.007 \mathrm{~m}^{3} \mathrm{~m}^{-3}$ on average at the surface and root zone, respectively). Enhancing the spatial resolution, however, does not significantly improve soil moisture estimates, particularly at the surface. Surface heat flux estimates from assimilating soil moisture data of different spatial or temporal resolutions are very similar.
\end{abstract}

\section{Introduction}

The dynamics of soil moisture and the partitioning of solar radiation at the land surface is key to hydrology (McCabe and Wood 2006), meteorology (Andrews et al. 2009), water resources management (Yang et al. 2018; Rigden and Salvucci 2015), and the terrestrial water cycle (Kumar et al. 2018). Soil moisture and surface heat fluxes can be measured with in situ flux networks (Dorigo et al. 2011; Baldocchi et al. 2001), but the extrapolation to regional scale is hindered by the uneven

Corresponding author: Yang Lu, y.lu-1@tudelft.nl distribution of observation networks as well as their heterogeneous nature in space (Jung et al. 2011). Remote sensing is a promising technique for large-scale land variable monitoring, but energy fluxes have no unique signature that is detectable by remote sensing instruments (Sini et al. 2008). Although soil moisture can be detected using microwave remote sensing, the data are generally provided with low spatial or temporal resolution. For example, data from microwave radiometers (Petropoulos et al. 2015) or scatterometers (Brocca et al. 2017) are of low temporal sampling frequency (2-3 days) and coarse spatial resolution $(30-50 \mathrm{~km})$, while data from some synthetic aperture 
radar systems (Lievens and Verhoest 2011; Malenovský et al. 2012; Paloscia et al. 2013; Bauer-Marschallinger et al. 2018) are of fine spatial resolution $(<3 \mathrm{~km})$ but longer revisit interval. Furthermore, only soil moisture near the surface $(<5 \mathrm{~cm})$ can be measured as a result of the limited sensing depth of microwave instruments, while the soil moisture at larger depth, which is crucial for vegetation transpiration, remains undetectable.

To generate soil moisture and surface heat fluxes at finer spatial and temporal resolution, many studies have focused on simulations using surface energy balance models or land surface models (Su 2002; Vinukollu et al. 2011; Huang et al. 2015; Bastiaanssen et al. 1998; Kilic et al. 2016). These models have wide applicability under different climatic conditions and over various land cover types but often require a large suite of input data (Sini et al. 2008). Simpler approaches have also been developed that are based on empirical relationships with local indicators at finer resolution such as land surface temperature (LST) and vegetation indices (Tang et al. 2010; Yang et al. 2015; Zhang et al. 2015; Sadeghi et al. 2017; Zhao et al. 2017). Such methods are easy to implement but largely rely on historical data for model calibration and are often region-dependent.

In a departure from the direct modeling approaches, some studies estimate surface heat fluxes by assimilating LST time series into simple heat transfer schemes (Castelli et al. 1999; Boni et al. 2001; Caparrini et al. 2003, 2004a,b; Crow and Kustas 2005; Bateni and Liang 2012; Bateni and Entekhabi 2012b; Bateni et al. 2013; Xu et al. 2014, 2015, 2016; Abdolghafoorian et al. 2017; Xu et al. 2018, 2019; He et al. 2018). Such methods only require a limited amount of input data and are easily transferable to other regions. By coupling the heat transfer scheme with a soil moisture transfer scheme, $\mathrm{Lu}$ et al. (2016) improved the methodology by jointly assimilating in situ measured soil moisture and LST data. The rationale is that available energy partitioning between the sensible and latent heat fluxes at the land surface influences the daytime evolution of surface thermal condition, therefore the partitioning of available energy can be inferred from a series of LST observations, while assimilating soil moisture data further constrains the partitioning (Bateni and Entekhabi 2012a). The key is to estimate two parameters: a bulk heat transfer coefficient under neutral atmosphere $C_{H N}$, which determines the sum of available energy, and a daytime constant evaporative fraction (EF), which represents the partitioning between sensible and latent heat fluxes. A subsequent study using LST data from the Geostationary Operational Environmental Satellite (GOES) mission and soil moisture data from the Soil Moisture Active Passive (SMAP) mission suggests that both surface heat flux and soil moisture estimates can be improved through the joint assimilation strategy ( $\mathrm{Lu}$ et al. 2017).

Despite the improved surface heat flux and soil moisture estimates, only soil moisture data from the passive microwave radiometer have been used for assimilation, of which the spatial resolution $(36 \mathrm{~km})$ and temporal sampling frequency (2-3 days) are both very coarse. As a result of the spatial heterogeneity and limited memory of soil moisture (Dunne and Entekhabi 2006), using coarse resolution soil moisture data may limit the capability of the method to characterize the spatial pattern and the temporal dynamics of soil wetness condition, which directly influences surface energy partitioning. With the abundance of soil moisture data sources, deriving soil moisture products of higher spatial resolution or temporal sampling frequency has become possible. Potential data sources include the Advanced Microwave Scanning Radiometer for Earth Observing System (AMSR-E; Njoku et al. 2003), the Advanced Scatterometer (ASCAT; Bartalis et al. 2007), the Advanced Microwave Scanning Radiometer-2 (AMSR-2; Imaoka et al. 2010), the Soil Moisture Ocean Salinity (SMOS; Kerr et al. 2001), as well as the enhanced and combined active/passive products from the SMAP mission (Entekhabi et al. 2010). On one hand, soil moisture data can be obtained at higher spatial resolution $(<10 \mathrm{~km})$ using radar or through downscaling procedures, which can better characterize the spatial heterogeneity of soil moisture caused by differences in meteorological conditions or surface properties. On the other hand, multisource soil moisture data from different remote sensing platforms contain complementary information on soil moisture dynamics, which has great potential for better depicting the temporal evolution of soil moisture through data fusion. This provides great opportunity to explore the question that given soil moisture data at higher spatial resolution or temporal sampling frequency, how much improvement can be expected in soil moisture and surface heat flux estimates.

This study is based on the methodology developed in Lu et al. (2017) and focuses on evaluating the impact of different soil moisture data on the soil moisture and surface heat flux estimates through data assimilation using two comparative experiments. In the first experiment, GOES LST time series are assimilated together with the SMAP Level-3 enhanced passive soil moisture product (L3_SM_P_E), which is provided at finer spatial resolution $(9 \mathrm{~km})$. In the second experiment, the soil moisture dataset used for assimilation is a merged product derived from the SMAP and the SMOS mission to obtain observations at higher sampling frequency (quasidaily). Results from both experiments are compared with 
those from Lu et al. (2017), which assimilated the SMAP Level-3 soil moisture product (L3_SM_P, 36 km/2-3 days) to evaluate the respective differences in surface heat flux estimates as well as soil moisture estimates at both the surface and the root zone. This is the first study that assimilates SMAP enhanced soil moisture product and the first to combine SMAP and SMOS products for improving surface heat flux and soil moisture estimates using data assimilation.

\section{Methodology}

\section{a. Dual-source energy balance scheme}

The methodology is based on a dual-source surface energy balance scheme, which was first proposed by Norman et al. (1995) and Kustas et al. (1996). In this scheme, the soil heat transfer is coupled to the soil water transfer. The key of this coupling is the tight interaction between soil moisture and latent heat flux: the modeled soil moisture influences the EF, which directly determines the partitioning of available energy at the land surface, while the estimated latent heat flux in turn serves as the sink term in the soil moisture modeling. The coupled heat and water transfer scheme is detailed in Lu et al. (2017).

The land surface is seen as a mixture of bare soil and vegetation canopy, and the total sensible $(H)$ and latent (LE) heat fluxes are derived as the weighted average of the contributions from the soil and the canopy

$$
\begin{aligned}
H & =f_{c} H_{c}+\left(1-f_{c}\right) H_{s}, \text { and } \\
\mathrm{LE} & =f_{c} \mathrm{LE}_{c}+\left(1-f_{c}\right) \mathrm{LE}_{s} \\
& =f_{c} \frac{\mathrm{EF}_{c}}{1-\mathrm{EF}_{c}} H_{c}+\left(1-f_{c}\right) \frac{\mathrm{EF}_{s}}{1-\mathrm{EF}_{s}} H_{s},
\end{aligned}
$$

where $H_{s}\left(\mathrm{LE}_{s}\right)$ and $H_{c}\left(\mathrm{LE}_{c}\right)$ are the sensible (latent) heat fluxes of the soil and the canopy, $\mathrm{EF}_{s}$ and $\mathrm{EF}_{c}$ (both unitless) are the EF values for the soil and canopy components, and $f_{c}$ (unitless) is the canopy fractional coverage.

To calculate $H_{s}$ and $H_{c}$, a parameter ( $C_{H N}$; unitless) needs to be estimated, which represents the impact of the landscape on the sum of the available energy under neutral atmospheric condition. The parameter $C_{H N}$ is influenced by the bare soil as well as the vegetation condition. Following Farhadi et al. (2014), $C_{H N}$ is estimated by

$$
C_{H N}=\exp (a+b \times \mathrm{LAI}) \text {. }
$$

Here the parameters $a$ and $b$ represent the influence from the soil and vegetation density, respectively, which will be estimated during data assimilation, and LAI (unitless) is the leaf area index.
To calculate $\mathrm{LE}_{s}$ and $\mathrm{LE}_{c}$, a key assumption is made that $\mathrm{EF}_{s}$ and $\mathrm{EF}_{c}$ stay constant during daytime (09001600 LT) when the sky is clear (Crago 1996; Crago and Brutsaert 1996; Gentine et al. 2007; Peng et al. 2013). Under this assumption, only one $\mathrm{EF}_{s}$ and one $\mathrm{EF}_{c}$ need to be estimated to calculate $\mathrm{LE}_{s}$ and $\mathrm{LE}_{c}$ at every time step during daytime, which greatly reduces the parameters to be estimated and makes the methodology more robust.

An arctangent-form relationship proposed by Dirmeyer et al. (2000) is improved to calculate reference values for $\mathrm{EF}_{s}$ and $\mathrm{EF}_{c}$ from the modeled soil moisture profile:

$$
\begin{aligned}
\mathrm{EF}_{s}^{\mathrm{ref}} & =\frac{2 \mathrm{EF}_{\text {max }}}{\pi} \arctan \left(\alpha_{s} \mathrm{SWI}_{s}\right), \\
\mathrm{EF}_{c}^{\mathrm{ref}} & =\frac{2 \mathrm{EF}_{\text {max }}}{\pi} \arctan \left(\alpha_{c} \mathrm{SWI}_{c}\right),
\end{aligned}
$$

where $\mathrm{EF}_{s}^{\mathrm{ref}}$ and $\mathrm{EF}_{c}^{\mathrm{ref}}$ are the reference values for $\mathrm{EF}_{s}$ and $\mathrm{EF}_{c}, \mathrm{EF}_{\max }$ is the maximum possible $\mathrm{EF}$ (assumed to be unity), $\mathrm{SWI}_{s}$ and $\mathrm{SWI}_{c}$ are the soil wetness indices calculated from the modeled soil moisture profile $(\mathrm{Lu}$ et al. 2017), and $\alpha_{s}$ and $\alpha_{c}$ are slope factors that control the shape of the curve and will be estimated during the assimilation. To account for the uncertainties in the estimation, $\mathrm{EF}_{s}$ and $\mathrm{EF}_{c}$ will be randomly sampled within a \pm 0.2 range around the reference values $(\mathrm{Lu}$ et al. 2016). A detailed description of the model is presented in Lu et al. (2017).

\section{b. Study area and data}

The methodology is applied over an area $\left(35.75^{\circ}-\right.$ $37.24^{\circ} \mathrm{N}, 96.72^{\circ}-98.21^{\circ} \mathrm{W}$ ) in the U.S. Southern Great Plains (SGP) shown in Fig. 1. The study area is covered by $30 \times 30 \mathrm{GOES} \mathrm{LST} \mathrm{cells} \mathrm{at} 0.05^{\circ}$ resolution, or by $4 \times$ 4 SMAP grid cells posted on a $36-\mathrm{km}$ Equal-Area Scalable Earth-2 (EASE-2) grid. This area is selected because of the relatively dense flux network. The area is generally flat and mostly covered by grassland and cropland, with a small fraction of urban area and water bodies. The dominant soil types are sandy loam and silt loam. In situ flux measurements are available at four stations from the Atmospheric Radiation Measurement (ARM) network. Parameters $H$ and LE are measured every $30 \mathrm{~min}$ by energy balance Bowen ratio (EBBR) instruments. In situ soil moisture observations are available at two stations from the U.S. Climate Reference Network (CRN; Bell et al. 2013) and the Soil Climate Analysis Network (SCAN; Schaefer et al. 2007), respectively. The soil moisture data are collected hourly at the depths of 5,10, 20,50 , and $100 \mathrm{~cm}$ from the surface.

The input data include forcing and ancillary datasets for the model simulation, and remote sensing datasets 


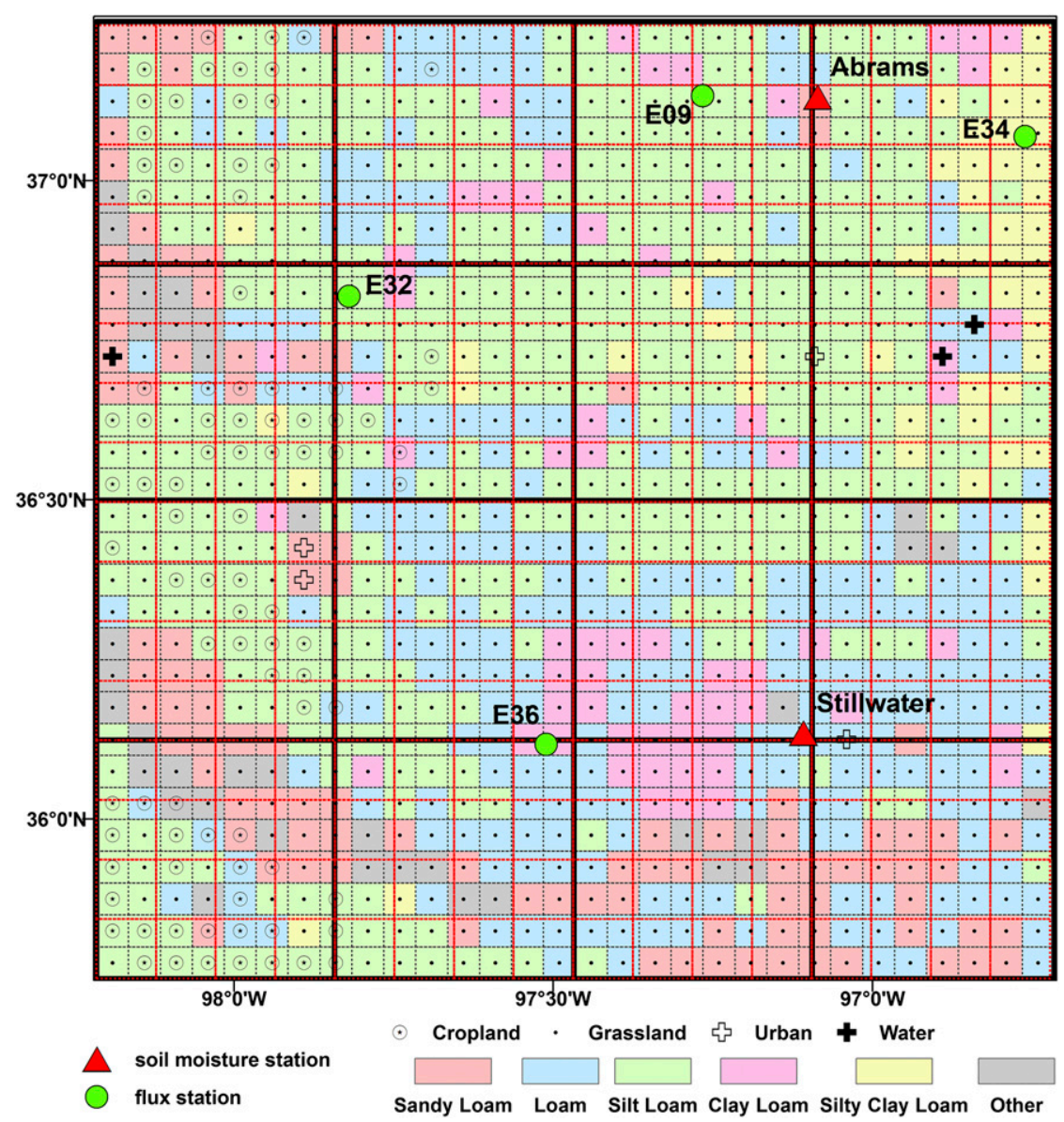

FIG. 1. Land cover and soil types in the study area. The thick black lines represent SMAP 36-km grids; the dashed lines in red and black represent SMAP 9-km grids and GOES LST grids, respectively.

for data assimilation. Precipitation forcing data are provided by the 3IMERGHH product from the Global Precipitation Mission (GPM; Hou et al. 2014; Huffman et al. 2015). Other meteorological data, including incoming shortwave $R_{s}^{\downarrow}$ and longwave radiation $R_{l}^{\downarrow}$, wind speed $U$, air temperature $T_{a}$, and air pressure $P_{a}$, are obtained from the North American Land Data Assimilation System project phase 2 (NLDAS-2; Xia et al. 2012). A summary of datasets is provided in Table 1.

The ancillary data used include data on soil texture, vegetation, and land cover. The $3-\mathrm{km}$ soil texture data, including sand and clay fraction and soil bulk density data, are provided by the National Snow and Ice Data Center (NSIDC; Das 2013). The soil texture data are used to calculate soil hydraulic properties using the ROSETTA software (Schaap et al. 2001). The LAI data (1 km, 8-day composite) used are the MCD15A2 product from the Moderate Resolution Imaging Spectroradiometer (MODIS; Knyazikhin et al. 1999). The land cover data are obtained from the ESA Climate Change Initiative (CCI; v1.6.1).

The data for assimilation include remote sensing observations for LST and soil moisture. The LST time series based on the geostationary observations from the GOES mission are obtained from the Copernicus Global Land Service (Freitas et al. 2013). Three remote sensing soil moisture datasets of different spatial and temporal resolution are involved in this study, including two operational products from the SMAP mission and a combined dataset from the SMAP and the SMOS mission. All soil moisture products are bias-corrected using the cumulative distribution function (CDF) matching approach before assimilation to reconcile for the difference between model simulations and observations in the long-term mean, variance and higher moments (De Lannoy and Reichle 2016).

One SMAP product is the Level-3 passive microwave soil moisture product (L3_SM_P). This data product is retrieved from the L-band microwave radiometer 
TABLE 1. Summary of datasets. The variables are explained in the text.

\begin{tabular}{|c|c|c|c|c|}
\hline \multirow[b]{2}{*}{ Category } & \multirow[b]{2}{*}{ Source } & \multirow[b]{2}{*}{ Dataset } & \multicolumn{2}{|c|}{ Original resolution } \\
\hline & & & Spatial & Temporal \\
\hline \multirow[t]{2}{*}{ Forcing data } & NLDAS-2 & $R_{s}^{\downarrow}, R_{l}^{\downarrow}, U, T_{a}, P_{a}$ & $0.125^{\circ}$ & $1 \mathrm{~h}$ \\
\hline & GPM & $P$ & $0.1^{\circ}$ & $30 \mathrm{~min}$ \\
\hline \multirow[t]{3}{*}{ Ancillary data } & NSIDC & Soil texture & $3 \mathrm{~km}$ & - \\
\hline & MODIS & LAI & $1 \mathrm{~km}$ & 8 days \\
\hline & ESA CCI & Land cover & $300 \mathrm{~m}$ & - \\
\hline \multirow[t]{4}{*}{ Data for assimilation } & SMAP & Soil moisture & $9 \mathrm{~km}$ & 2-3 days \\
\hline & & & $36 \mathrm{~km}$ & \\
\hline & SMOS-IC & & $35-50 \mathrm{~km}$ & \\
\hline & GOES & LST & $0.05^{\circ}$ & $1 \mathrm{~h}$ \\
\hline
\end{tabular}

measurements, with a typical spatial resolution of $36 \mathrm{~km}$ and a revisit interval of 2-3 days (Entekhabi et al. 2014). The other SMAP product is the SMAP Level-3 enhanced passive microwave soil moisture product (L3_SM_P_E). L3_SM_P_E distinguishes itself from the L3_SM_P in that the soil moisture retrievals are posted on $9-\mathrm{km}$ grids instead of $36-\mathrm{km}$ grids. This is achieved by first interpolating the original Level-1B brightness temperature observations using the BackusGilbert optimal interpolation technique (Chan et al. 2018) to take advantage of the overlapping radiometer footprints. The interpolated brightness temperature "observations" are then used as the input to the baseline algorithm to generate soil moisture retrievals at $9-\mathrm{km}$ resolution. Comparison against in situ observations suggests that the performance of the $9-\mathrm{km}$ enhanced soil moisture product is comparable to that of the $36-\mathrm{km}$ soil moisture product (Chan et al. 2018).

In addition, a merged product from the SMAP L3_SM_P product and the SMOS-IC (SMOS-INRACESBIO) product is also used. SMOS-IC differs from the operational SMOS Level-3 soil moisture product in the treatment of heterogeneous grid cells. The main goal of this product is to be as independent as possible from ancillary data. To achieve this goal, SMOS-IC considers grid cells as homogeneous to avoid uncertainties caused by ancillary data, which are used to characterize the heterogeneity of the grid cells. The schemes used for vegetation scattering albedo and soil roughness correction are also different. SMOS-IC product is posted on the same grids with the operational SMOS data. Comparison against European Centre for MediumRange Weather Forecasts (ECMWF) soil moisture outputs suggests that SMOS-IC product yields higher correlations and lower unbiased RMSD (ubRMSD) than the operational SMOS soil moisture product over most pixels globally (Fernandez-Moran et al. 2017). Here SMOS-IC data are used in a data fusion process to fill in the gaps of SMAP L3_SM_P product between two SMAP descending overpasses (0600 LT). The original SMOS-IC data are first interpolated to the same grids as SMAP L3_SM_P at 36-km resolution. The interpolated SMOS-IC data are rescaled to model simulations and then used to fill in the gaps of SMAP L3_SM_P observations to achieve higher temporal sampling frequency. For days when only SMOS-IC data are available, the data are inserted into the SMAP L3_SM_P data stream as "additional observations." On days with both SMAP L3_SM_P and SMOS overpasses, SMOS-IC data are not used. This is to enhance the temporal sampling frequency of soil moisture data while minimizing the perturbation of the original SMAP L3_SM_P data dynamics.

\section{c. Data assimilation strategy}

Soil moisture data and LST time series are assimilated into the coupled heat and water transfer model using different assimilation approaches. The main reason is the contrasting spatial and temporal resolution gap between the two datasets. As the spatial and temporal resolution of LST data is much higher than that of the soil moisture data, if assimilated jointly within the daytime window, the information contained in the soil moisture observations will be masked by the large number of LST observations. In addition, soil moisture observations are like a "snapshot" of the surface and represent instantaneous soil wetness condition, therefore filtering is better suited to update soil moisture state at the satellite overpass time. While the information on surface energy partitioning can be derived from the temporal evolution of a series of LST observations instead of the magnitude of each individual observation, hence smoothing is used instead of filtering for LST assimilation.

Here soil moisture data are assimilated using a particle filter (PF) at $0600 \mathrm{LT}$, while LST time series are assimilated using an adaptive particle batch smoother (APBS) within the daytime window (0900-1600 LT) when EF can be assumed invariant under clear-sky condition. The soil moisture profile is updated through soil moisture 
assimilation, while $T_{s}$ and $T_{c}$ as well as the four parameters ( $a$ and $b$ for calculating $C_{H N}$, and $\alpha_{s}$ and $\alpha_{c}$ for estimating reference EF values) are updated during the LST assimilation. The hybrid data assimilation strategy was proposed by Lu et al. (2017), and proved effective in improving soil moisture states as well as surface heat flux estimates using remote sensing data. A detailed description is provided in Lu et al. (2017).

\section{d. Experiment implementation}

The experiment is run from day of year (DOY) 155 to 274 (120 days) in 2015 at a 30 -min time step and $0.05^{\circ}$ resolution. Six-hundred particles are used, which prove sufficient from a sensitivity test. Since the forcing data are coarser than the model grid cell, a "drop in the bucket" strategy is used to extract forcing data for each model grid cell. The forcing data from NLDAS-2 are also assumed representative during the 1 -h period to accommodate the temporal resolution gap with model simulations. To account for the uncertainty of the forcing data as well as their heterogeneity within the data grid cells, perturbations are added which are summarized in Table 2. The perturbations are determined based on values suggested by previous studies (Luo et al. 2003; Dong et al. 2016; Lu et al. 2017). Sensitivity analysis indicates that model estimates are robust as long as the perturbations are within a reasonable range. The modeling errors for the heat and water transfer are assumed to be $0.1 \mathrm{~K}$ and $0.001 \mathrm{~m}^{3} \mathrm{~m}^{-3}$ following $\mathrm{Lu}$ et al. (2016). The observation errors for remote sensing soil moisture and LST data are assumed to be $0.04 \mathrm{~m}^{3} \mathrm{~m}^{-3}$ (Chan et al. 2016; Cai et al. 2017; Colliander et al. 2017) and $3 \mathrm{~K}$ (Lu et al. 2016), respectively. The ancillary data are spatially aggregated to the modeling scale, and the LAI data are also temporally interpolated to derive daily LAI values for each model grid cell.

There are four parameters to be determined through data assimilation: $a$ and $b$ for calculating $C_{H N}$, and $\alpha_{s}$ and $\alpha_{c}$ for estimating reference EF values. Initially, the parameter values are uniformly sampled from a given range. The ranges for $a$ and $b$ are $(-7,-5)$ and $(0,1)$, respectively, following Abdolghafoorian et al. (2017), and an initial range of $(1,10)$ is used for $\alpha_{s}$ and $\alpha_{c}$ based on values from Dirmeyer et al. (2000), which allows sufficient EF dynamics under different soil wetness condition.

During daytime (0900-1600 LT), $\mathrm{LE}_{s}$ and $\mathrm{LE}_{c}$ are estimated from $H_{s}$ and $H_{c}$, and $G$ is estimated as the residual of energy balance and is used to propagate $T_{s}$. From 1600 to $0900 \mathrm{LT}$ the next day when EF can no longer be assumed constant, $G$ is estimated as a random fraction (between $0 \%$ and $30 \%$ ) of $R_{n s}$ (Choudhury et al. 1987; French et al. 2003) and used to propagate
TABLE 2. Perturbations used for forcing data.

\begin{tabular}{clc}
\hline \hline Forcing & \multicolumn{1}{c}{ Perturbation } & Standard deviation \\
\hline$R_{s}^{\downarrow}$ & Gaussian, multiplicative & $\times, 0.1$ \\
$R_{l}^{\downarrow}$ & Gaussian, multiplicative & $\times, 0.1$ \\
$U$ & Gaussian, additive & $1 \mathrm{~m} \mathrm{~s}^{-1}$ \\
$T_{a}$ & Gaussian, additive & $5 \mathrm{~K}$ \\
$P$ & Lognormal, multiplicative & $\times, 0.2$ \\
\hline
\end{tabular}

$T_{s}$, and $T_{c}$ is assumed equal to $T_{s}$. This enables the model to run continuously outside the daytime window so that the temperature states only need to be initialized once at the beginning, while this study focuses on flux estimates in the daytime window. More details can be found in Lu et al. (2016).

Two assimilation experiments are conducted to evaluate the impact of spatial resolution and temporal sampling frequency of soil moisture data. In the first experiment (hereafter DA $_{9 \mathrm{~km}}$ ), the SMAP L3_SM_P_E data at 9-km resolution are assimilated together with GOES LST data. In the second experiment (hereafter $\left.\mathrm{DA}_{\text {merge }}\right)$, the soil moisture data assimilated are the merged dataset at $36-\mathrm{km}$ resolution but with finer sampling frequency. Results from both experiments are compared with those from a previous study ( $\mathrm{Lu}$ et al. 2017), which assimilated the spatiotemporally coarse (36 km, 2-3 days) SMAP L3_SM_P product (hereafter $\mathrm{DA}_{36 \mathrm{~km}}$ ), and from the open-loop (no assimilation case, hereafter OL) runs.

\section{Results and discussion}

\section{a. Improving spatial resolution of soil moisture observations}

The observed mean surface soil moisture $(0-5 \mathrm{~cm}$, hereafter SSM) during the study period for the study area is plotted in Fig. 2 to examine the consistency and difference between the SMAP 36-km (L3_SM_P) product and 9-km (L3_SM_P_E) product. Both products show similar SSM patterns in the study area, demonstrating a clear dry-wet gradient from the southwest to the northeast. The areal mean SSM values generally agree well with each other, and the SMAP 9-km product better characterizes the spatial heterogeneity of SSM as a result of the enhanced spatial resolution. This is expected since both products are retrieved from the same original brightness temperature observations. The largest difference appears in the northeast of the area [grid cell $(2,1)$ of the SMAP $36-\mathrm{km}$ product], which is influenced by the relatively high fraction of water body. A large lake exists in the northern part of the grid cell, which would greatly lower the observed brightness temperature and 



FIG. 2. Observed mean SSM during the study period for the study area from the SMAP 36-km (L3_SM_P) product and 9-km (L3_SM_P_E) product.

make the SSM retrieval less reliable. The soil moisture retrievals in that grid cell therefore should be used with caution.

The SSM estimates from $\mathrm{DA}_{36 \mathrm{~km}}$ and $\mathrm{DA}_{9 \mathrm{~km}}$ are assessed at Abrams and Stillwater in Fig. 3 using metrics of RMSD, ubRMSD, bias, and $R$. The model simulations are influenced by the disagreement between GPM retrievals and in situ precipitation measurements as well the deficiencies in the texture-derived soil hydraulic properties, which are more evident at Stillwater. The difference between SMAP 36- and 9-km soil moisture products are generally very small, particularly at Stillwater where there are many long dry-down events during the study period. The maximum difference however, can reach over $0.05 \mathrm{~m}^{3} \mathrm{~m}^{-3}$ at both stations on a couple of days. The large differences mainly occur after rain events, which may be caused by the SSM heterogeneity within the $36-\mathrm{km}$ footprint caused by the uneven distribution of precipitation and soil hydraulic properties. Experiments $\mathrm{DA}_{36 \mathrm{~km}}$ and $\mathrm{DA}_{9 \mathrm{~km}}$ both show considerable improvement in SSM estimates over the OL simulations, but the improvement is comparable in terms of the statistical metrics. This may imply that the spatial variation of SSM is small within one $36-\mathrm{km}$ grid cell in the study area, and that the SSM estimates are to a large extent dependent on the quality of the precipitation input. As a result, assimilating soil moisture data with enhanced spatial resolution only leads to limited improvement in SSM estimates, despite the finer spatial patterns the dataset reveals.

A statistical comparison of 30-min SSM estimates from $\mathrm{DA}_{36 \mathrm{~km}}$ and $\mathrm{DA}_{9 \mathrm{~km}}$ in the study area is conducted to evaluate the consistency between the two assimilation strategies. As is shown in Fig. 4, the $R^{2}$ is above 0.95 over most of the area, indicating a very good agreement in the estimated SSM time series. This again proves the dominance of precipitation forcing on SSM dynamics. The ubRMSD and the bias are also very small throughout the study area, which confirms the comparable performance by assimilating soil moisture observations at 36- and 9-km scale.

The performance of data assimilation is also assessed for the second layer $(5-15 \mathrm{~cm})$ and root-zone soil moisture (hereafter RZSM) in Fig. 5. A small difference exists between the thickness of modeled $(90 \mathrm{~cm})$ and observed $(100 \mathrm{~cm})$ soil column. To calculate RZSM, the model simulations are averaged along the soil column weighted by their respective layer thicknesses to derive a RZSM for the $0-90-\mathrm{cm}$ soil column. The in situ soil moisture measurements are first linearly interpolated to get a soil moisture profile, and then integrated to get the RZSM for the $0-100-\mathrm{cm}$ soil column. Both $\mathrm{DA}_{36 \mathrm{~km}}$ and $\mathrm{DA}_{9 \mathrm{~km}}$ show correction of model simulations toward the independent in situ measurements, particularly in the second layer where the correlation with SSM is stronger. $\mathrm{DA}_{9 \mathrm{~km}}$ slightly outperforms $\mathrm{DA}_{36 \mathrm{~km}}$, which is more evident in Abrams where the soil hydraulic properties are more plausible. Large bias exists between model simulations and in situ measurements for RZSM, which is mainly caused by the initialization error of soil moisture profile, and the assimilation system is not designed to quickly correct the bias. For initialization, the soil moisture profile is assumed uniform with randomly sampled soil moisture, since little is known about the initial soil moisture state along the soil column. Remote sensing soil moisture observations are assimilated before the deep layer soil 


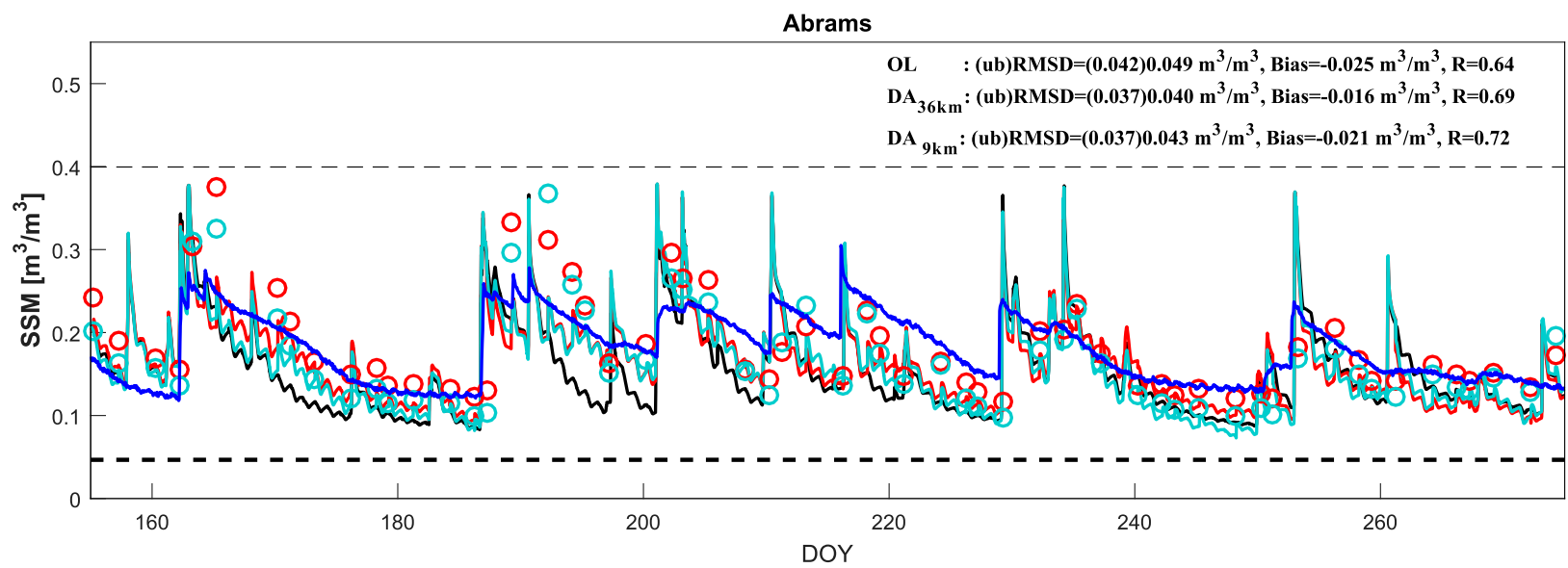

Stillwater

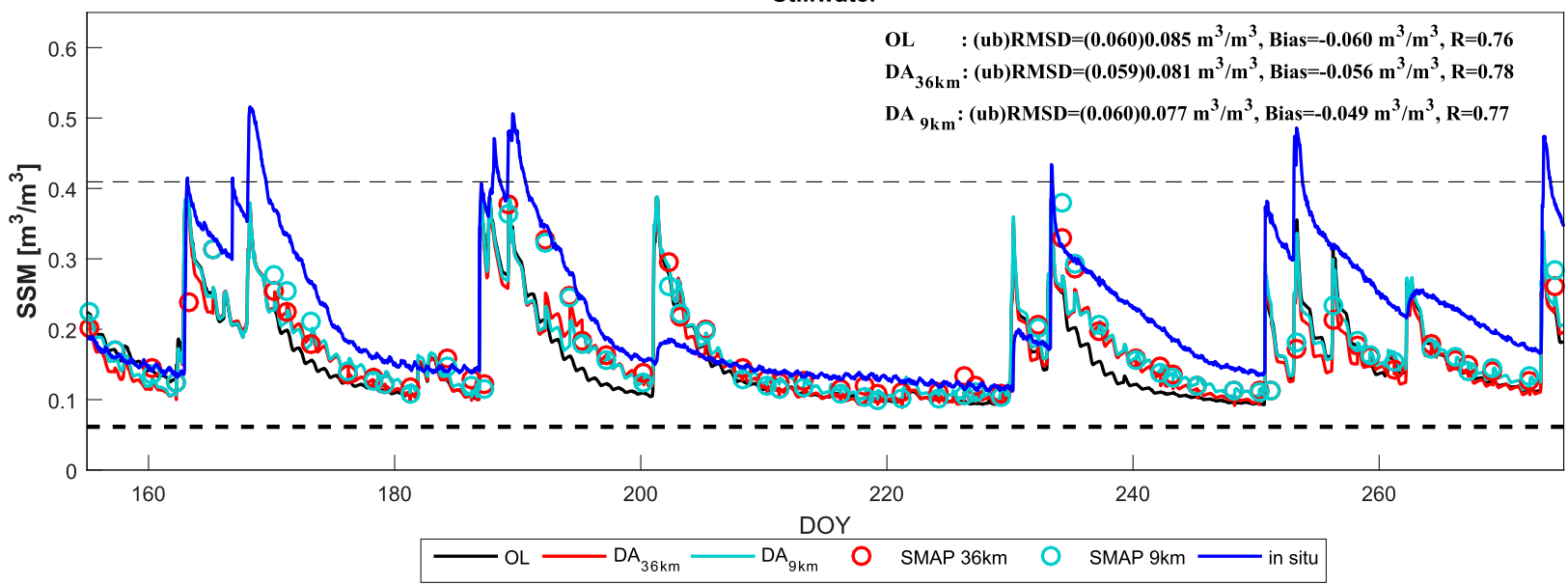

FIG. 3. Assessment of SSM estimates from $\mathrm{DA}_{36 \mathrm{~km}}$ and $\mathrm{DA}_{9 \mathrm{~km}}$ against in situ measurements. The thick and thin dashed lines represent residual and saturated soil moisture used in the modeling, respectively.

moisture has reached its climatological values. Consequently, the updated deep layer soil moisture will be lower than the measurements. In addition, in situ observations suggest that soil moisture is almost always near saturation in the deepest layer with little dynamics, which further contributes to the large bias.
The 30-min $H$ and LE estimates from $\mathrm{DA}_{36 \mathrm{~km}}$ and $\mathrm{DA}_{9 \mathrm{~km}}$ are compared with those from OL and in situ measurements at the four flux stations in the study area in Fig. 6. Both $\mathrm{DA}_{36 \mathrm{~km}}$ and $\mathrm{DA}_{9 \mathrm{~km}}$ show considerable improvement on flux estimates over OL simulations, particularly for LE estimates. This mainly benefits
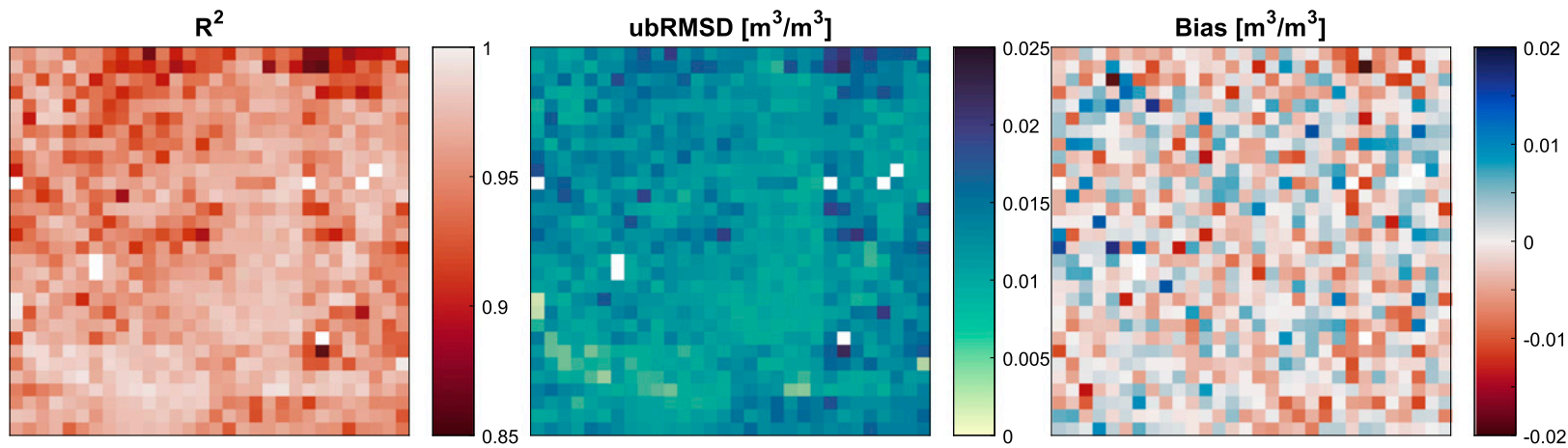

FIG. 4. Statistical comparison of 30-min SSM time series from $\mathrm{DA}_{9 \mathrm{~km}}$ with those from $\mathrm{DA}_{36 \mathrm{~km}}$. Grid cells with dominant land cover types of water body or urban area are masked out. 

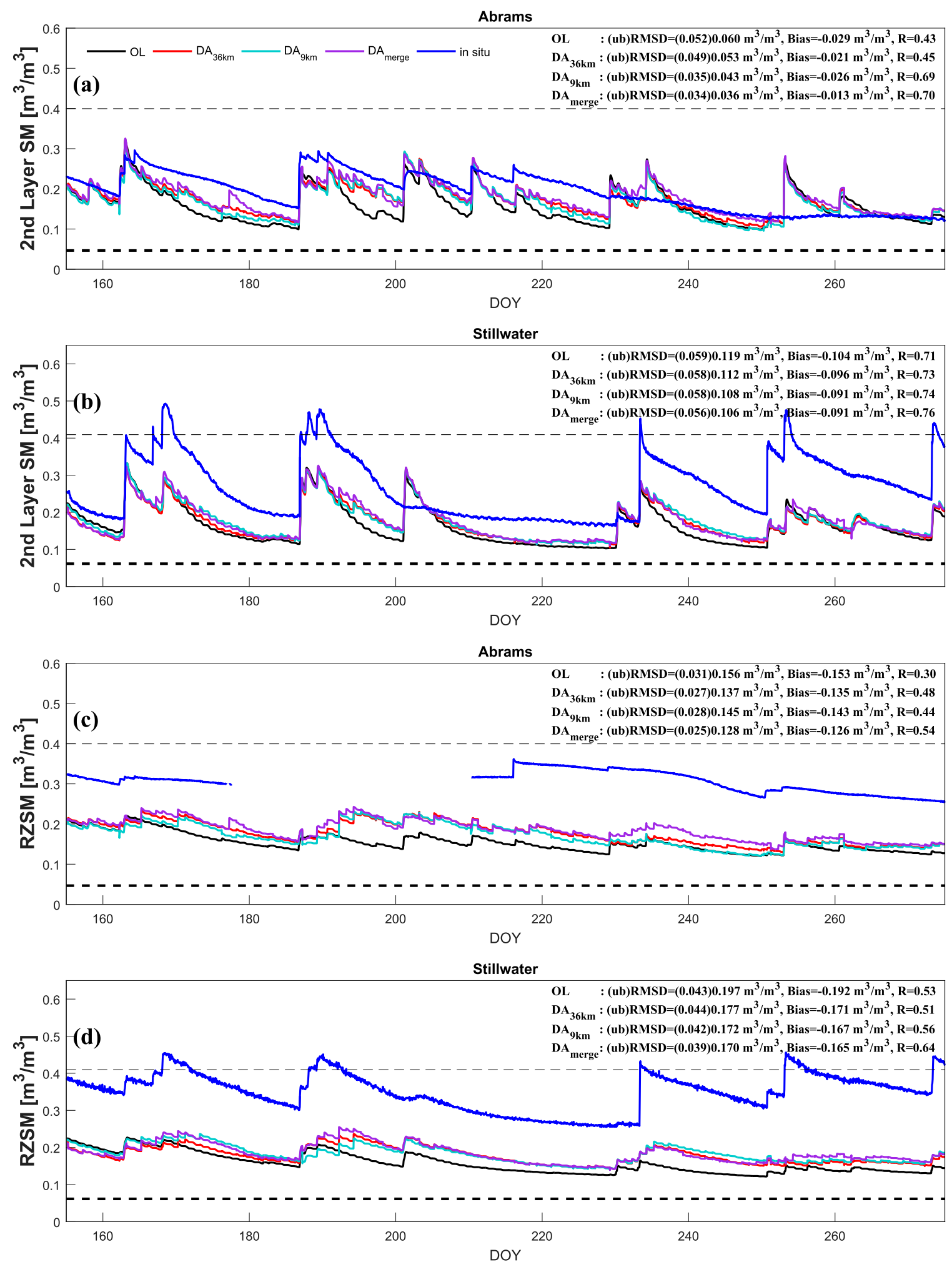

FIG. 5. Assessment of the (a),(b) second layer (5-15 cm) and (c),(d) RZSM from DA $\mathrm{DA}_{36 \mathrm{~km}}$, DA 9km $_{\text {, and }}$ DA $\mathrm{A}_{\text {merge }}$ against in situ measurements. The thick and thin dashed lines represent residual and saturated soil moisture used in the modeling, respectively. 


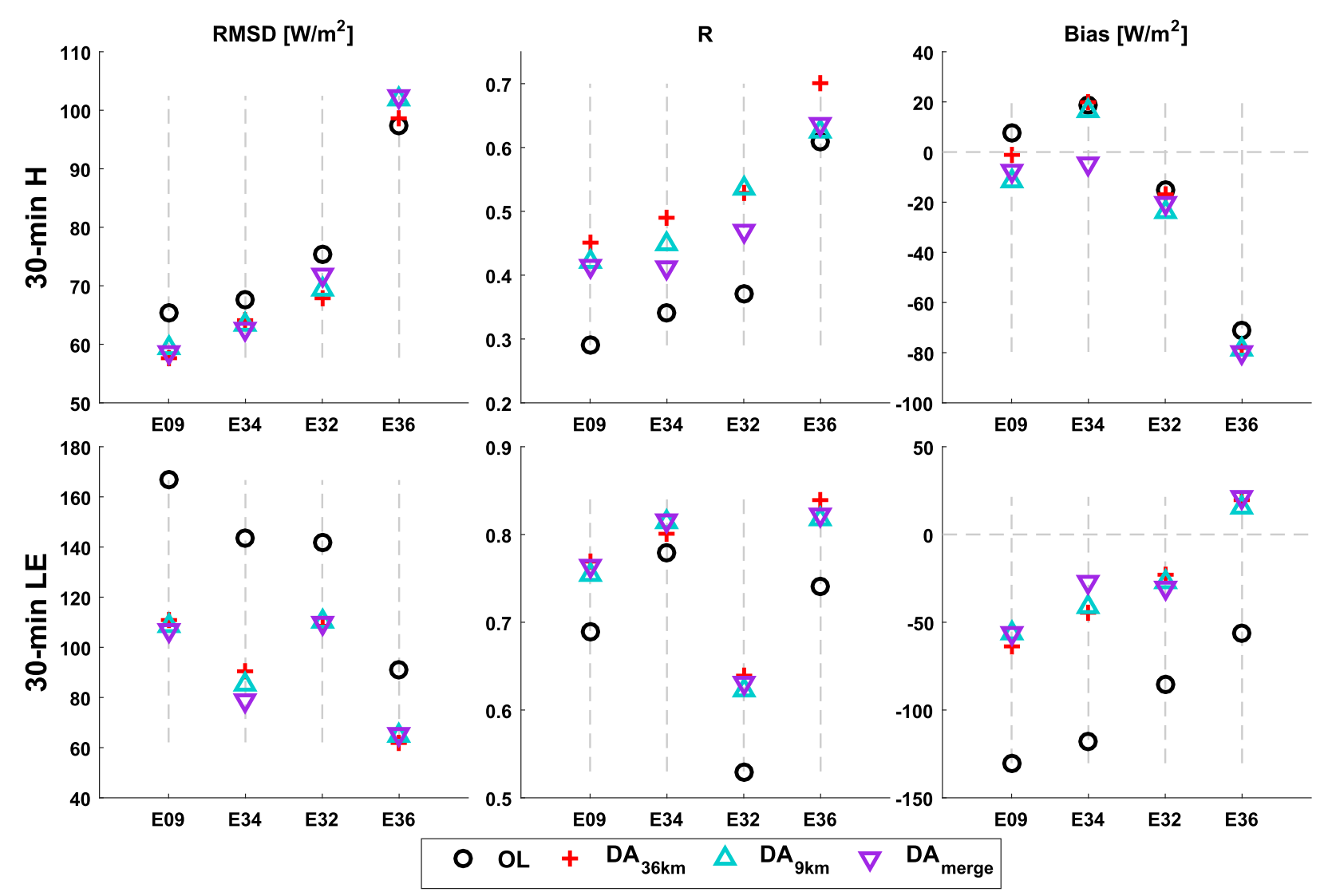

FIG. 6. Statistical comparison of 30-min $H$ and LE estimates from $\mathrm{DA}_{36 \mathrm{~km}}, \mathrm{DA}_{9 \mathrm{~km}}$, and $\mathrm{DA}_{\text {merge }}$ at four flux stations.

from the better characterization of soil moisture dynamics after data assimilation. The $H$ and LE estimates at daytime scale (0900-1600 LT) yield similar results (not shown). Generally, the estimates from $\mathrm{DA}_{36 \mathrm{~km}}$ and $\mathrm{DA}_{9 \mathrm{~km}}$ are very similar. This is understandable since the soil moisture estimates at the surface and deeper layers are very similar from both strategies, which results in comparable energy flux partitioning at the land surface.

\section{b. Improving temporal resolution of soil moisture observations}

Before merging the SMAP L3_SM_P product and the SMOS-IC product to obtain soil moisture data with higher sampling frequency, the histograms of SSM data from the original SMAP L3_SM_P product and SMOSIC product (mapped to $36-\mathrm{km}$ scale) are plotted in Fig. 7 to check the consistency between the two products using all the available data. SSM from both products falls in the range of $(0,0.45)$, and the distributions also show similar patterns. SMAP L3_SM_P product shows a slight wet bias compared to the SMOS-IC product, which may be caused by the difference in the remote sensing platforms or the soil moisture retrieval algorithms. Overall, the two products agree very well with each other in both the distribution and the soil moisture magnitude, which lays a good basis for data fusion. The SMOS-IC observations are then inserted into the SMAP L3_SM_P time series as "additional observations" following the procedures described in section $2 b$.

The availability of soil moisture observations from the SMAP L3_SM_P product and SMOS-IC product in the 16 grid cells at $36-\mathrm{km}$ scale in the study area is shown in Fig. 8. On average, there are 59 SMAP L3_SM_P observations and 40.7 SMOS-IC observations available during the 120-day study period for each grid cell. Out of the 40.7 SMOS-IC observations, 24.2 observations are from days without SMAP overpass, showing great potential for providing additional soil moisture information. When data fusion is conducted, the merged product provides 83.2 observations for each grid cell on average, which is a $41 \%$ increase over the SMAP L3_SM_P product. The merged product with enhanced temporal sampling frequency is expected to better characterize soil moisture dynamics.

The SSM estimates from $\mathrm{DA}_{36 \mathrm{~km}}$ and $\mathrm{DA}_{\text {merge }}$ are compared at the two soil moisture stations in Fig. 9. 


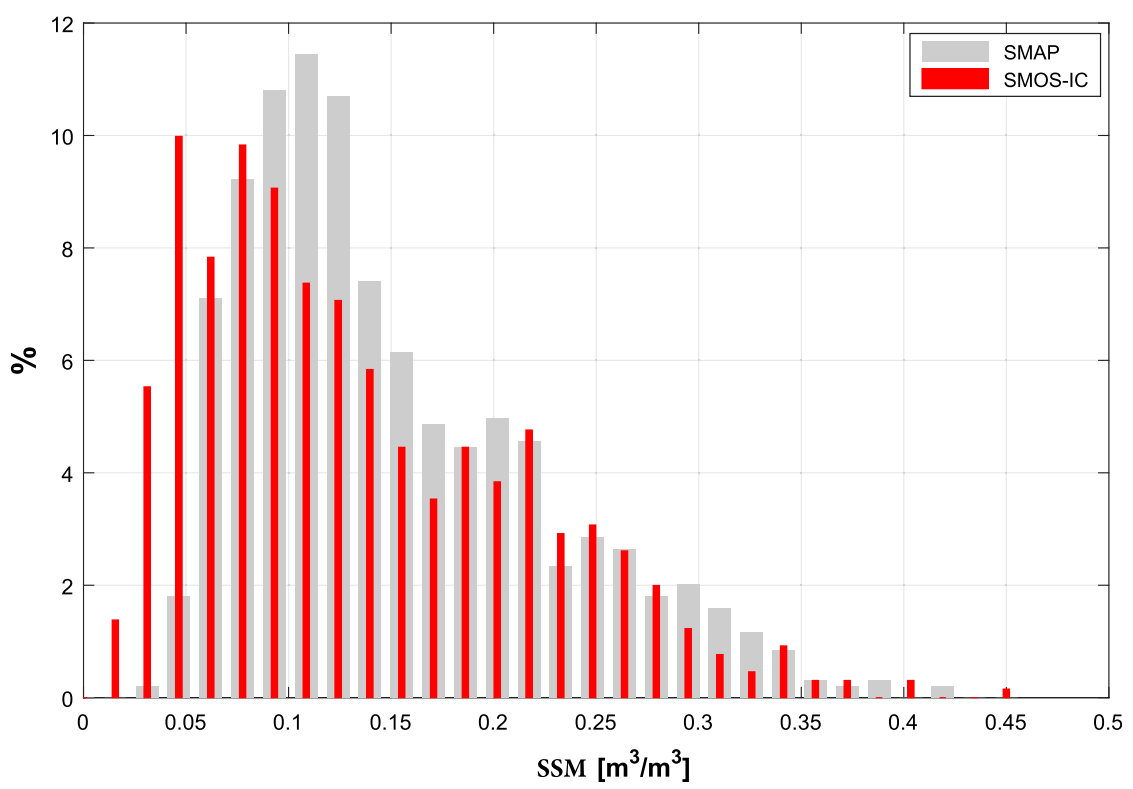

FIG. 7. Histograms of the SMAP L3_SM_P product and SMOS-IC product in the study area during the study period at $36-\mathrm{km}$ scale using all available data.

The difference between the two strategies is most evident for periods when there are more frequent additional observations from SMOS-IC. As a result, the SSM estimates from $\mathrm{DA}_{\text {merge }}$ are more strongly corrected toward the observations, which is also revealed by the reduced bias. In terms of statistical metrics, $\mathrm{DA}_{\text {merge }}$ outperforms $\mathrm{DA}_{36 \mathrm{~km}}$ in SSM estimates, particularly in Abrams. The ubRMSD, RMSD, bias, and $R$ are all improved in $\mathrm{DA}_{\text {merge }}$, while the largest improvement is seen in the bias metric. This is mainly caused by the stronger constraint on soil moisture simulation through more frequent SSM assimilation. The uncertainties in soil moisture simulations can become larger with time as a result of the inaccurate soil hydraulic properties or the deficiencies in remote sensing precipitation input ( $\mathrm{Lu}$ et al. 2017), which can be mitigated by updating soil moisture states toward observations through data assimilation. With enhanced temporal sampling frequency, assimilating the merged soil moisture product enables more frequent soil moisture updates, which essentially prevents the estimation bias from becoming too large. As a result, an evident decrease in bias is seen at both stations.

The estimates of soil moisture of the second layer and the RZSM from DA $\mathrm{D}_{\text {merge }}$ are also plotted in Fig. 5. Experiment $\mathrm{DA}_{\text {merge }}$ improves soil moisture estimates



FIG. 8. The availabilities of the SMAP L3_SM_P product and SMOS-IC product in the study area during the study period. The colors indicate only SMAP L3_SM_P data available (red), only SMOS-IC data available (yellow), both data available (blue), and no data available (gray). 

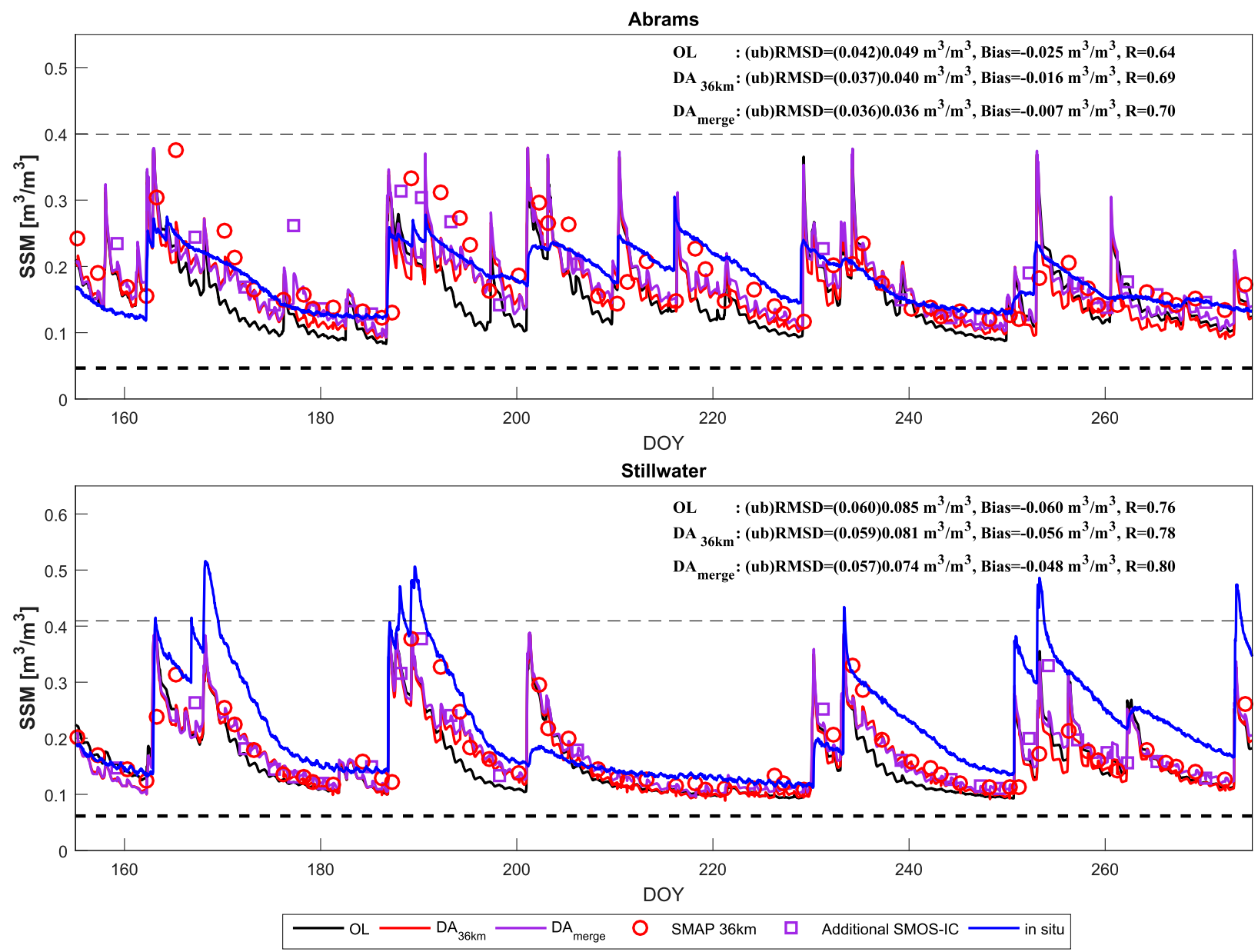

FIG. 9. Assessment of SSM estimates from $\mathrm{DA}_{36 \mathrm{~km}}$ and $\mathrm{DA}_{\text {merge }}$ against in situ measurements. The thick and thin dashed lines represent residual and saturated soil moisture used in the modeling, respectively.

in both the second layer as well as the root zone, particularly in the second layer since it is more closely correlated with the SSM observations from remote sensing. The improvement is more evident in Abrams, since the precipitation forcing data and soil hydraulic properties agree better with in situ observations. As a result of the stronger and more frequent constraint on soil moisture dynamics, $\mathrm{DA}_{\text {merge }}$ performs best among all the three data assimilation strategies $\left(\mathrm{DA}_{36 \mathrm{~km}}, \mathrm{DA}_{9 \mathrm{~km}}, \mathrm{DA}_{\text {merge }}\right)$ based on all the statistical metrics. This implies that the soil moisture heterogeneity in the study area is not pronounced and that observations at $36-\mathrm{km}$ scale can well represent the soil wetness condition. As a result, improving the temporal sampling frequency may be more meaningful by improving the characterization of soil wetness dynamics. Table 3 summarizes all the statistical metrics for soil moisture from remote sensing and model simulations against in situ measurements.

The 30-min $H$ and LE estimates from $\mathrm{DA}_{36 \mathrm{~km}}$ and $\mathrm{DA}_{\text {merge }}$ are also compared in Fig. 6. Despite the improvement in soil moisture estimates, no evident improvement can be seen in the $H$ and LE estimates from $\mathrm{DA}_{\text {merge }}$ compared to those from $\mathrm{DA}_{36 \mathrm{~km}}$. Since the reference EF values are determined by soil moisture using an arctangent relationship, a small difference in soil moisture will not have large influence on the reference EF values, especially when the soil moisture is high and the reference EF plateaus. In addition, the \pm 0.2 uncertainty given to the reference $\mathrm{EF}$ values further reduces the EF variations caused by the difference in soil moisture estimates. As a result, the influence of slightly improved soil moisture estimates on flux estimates is limited. The comparison is similar at daytime scale (not shown).

\section{Conclusions}

In this study, the impact of enhanced spatial and temporal resolution of soil moisture data on the estimates of soil moisture and surface heat fluxes through data assimilation is evaluated using two comparative experiments in 
TABLE 3. Statistical assessment of remote sensing soil moisture observations and model estimates against in situ measurements. The best performance in each category is shown in bold.

\begin{tabular}{|c|c|c|c|c|c|c|c|}
\hline & & \multicolumn{3}{|c|}{ Abrams } & \multicolumn{3}{|c|}{ Stillwater } \\
\hline & & ubRMSD & Bias & $R$ & ubRMSD & Bias & $R$ \\
\hline \multirow[t]{3}{*}{ Observations } & $\mathrm{SMAP}_{36 \mathrm{~km}}$ & 0.047 & 0.001 & 0.62 & 0.068 & -0.046 & 0.68 \\
\hline & $\mathrm{SMAP}_{9 \mathrm{~km}}$ & 0.047 & -0.014 & 0.64 & 0.064 & -0.044 & 0.71 \\
\hline & SMAP+SMOS-IC & 0.045 & 0.006 & 0.65 & 0.063 & -0.048 & 0.74 \\
\hline \multirow[t]{4}{*}{ SSM } & $\mathrm{OL}$ & 0.042 & -0.025 & 0.64 & 0.060 & -0.060 & 0.76 \\
\hline & $\mathrm{DA}_{36 \mathrm{~km}}$ & 0.037 & -0.016 & 0.69 & 0.059 & -0.056 & 0.78 \\
\hline & $\mathrm{DA}_{9 \mathrm{~km}}$ & 0.037 & -0.021 & 0.72 & 0.060 & -0.049 & 0.77 \\
\hline & $\mathrm{DA}_{\text {merge }}$ & 0.036 & -0.007 & 0.70 & 0.057 & -0.048 & 0.80 \\
\hline \multirow[t]{4}{*}{ Second layer } & $\mathrm{OL}$ & 0.052 & -0.029 & 0.43 & 0.059 & -0.104 & 0.71 \\
\hline & $\mathrm{DA}_{36 \mathrm{~km}}$ & 0.049 & -0.021 & 0.45 & 0.058 & -0.096 & 0.73 \\
\hline & $\mathrm{DA}_{9 \mathrm{~km}}$ & 0.035 & -0.026 & 0.69 & 0.058 & -0.091 & 0.74 \\
\hline & $\mathrm{DA}_{\text {merge }}$ & 0.034 & -0.013 & 0.70 & 0.056 & -0.091 & 0.76 \\
\hline \multirow[t]{4}{*}{ RZSM } & $\mathrm{OL}$ & 0.031 & -0.153 & 0.30 & 0.043 & -0.192 & 0.53 \\
\hline & $\mathrm{DA}_{36 \mathrm{~km}}$ & 0.027 & -0.135 & 0.48 & 0.044 & -0.171 & 0.51 \\
\hline & $\mathrm{DA}_{9 \mathrm{~km}}$ & 0.028 & -0.143 & 0.44 & 0.042 & -0.167 & 0.56 \\
\hline & $\mathrm{DA}_{\text {merge }}$ & 0.025 & -0.126 & 0.54 & 0.039 & -0.165 & 0.64 \\
\hline
\end{tabular}

a predominantly grassland area in the Southern Great Plains. In the first experiment $\left(\mathrm{DA}_{9 \mathrm{~km}}\right)$, the SMAP L3_SM_P_E product ( $9 \mathrm{~km}, 2-3$ days) is assimilated together with GOES LST time series. In the second experiment ( $\left.\mathrm{DA}_{\text {merge }}\right)$, the soil moisture product assimilated is a merged dataset $(36 \mathrm{~km}$, quasi-daily) from SMAP and SMOS-IC products. Results from both experiments are compared to those from a previous study $\left(\mathrm{DA}_{36 \mathrm{~km}}\right)$, which assimilated the SMAP L3_SM_P product (36 km, 2-3 days), as well as from a no-assimilation case (OL), and the impact of enhanced resolution is discussed.

Although the 9-km SMAP L3_SM_P_E product is expected to better characterize the spatial heterogeneity of soil moisture, the improvement in soil moisture of the surface and deeper layers is in general not evident compared to those from $\mathrm{DA}_{36 \mathrm{~km}}$. This may be attributable to the limited soil moisture heterogeneity in the study area, therefore the improvement in soil moisture estimates by enhancing the soil moisture observations to 9-km scale is limited.

Assimilating the merged soil moisture product outperforms all other assimilation strategies in soil moisture estimates of both the surface and the root zone at the two soil moisture stations. This benefits from the stronger constraints put on soil moisture dynamics. As a result of the enhanced temporal sampling frequency, soil moisture states are updated more frequently in $\mathrm{DA}_{\text {merge }}$, which prevents the simulation error from becoming too large. This indicates that soil moisture data with enhanced temporal resolution indeed contain useful information that helps to improve soil moisture estimates at both the land surface and the root zone.

Despite the differences in soil moisture estimates, no evident improvement in surface heat flux estimates can be seen from either $\mathrm{DA}_{9 \mathrm{~km}}$ or $\mathrm{DA}_{\text {merge }}$. This is expected in $\mathrm{DA}_{9 \mathrm{~km}}$ since the soil moisture estimates are similar with those from $\mathrm{DA}_{36 \mathrm{~km}}$. In $\mathrm{DA}_{\text {merge }}$, the improvement in soil moisture estimates does not lead to improvement in flux estimates as a result of the uncertainties in EF estimates. This may imply that surface energy partitioning cannot be further improved by improving soil moisture states alone, and that information from other data sources should be incorporated to further constrain EF, for example, vegetation dynamics (Bateni et al. 2014).

Here the merged soil moisture data are generated directly from the SMAP and SMOS-IC soil moisture products for simplicity and easier comparison with previous studies (Lu et al. 2017). It should be noted that the aim is not to find the optimal approach for SMAP and SMOS-IC data fusion but to evaluate the impact when more frequent soil moisture sampling becomes available. A more rigorous data fusion should convert brightness temperature observations from SMOS to SMAP-like data using methods such as that proposed by De Lannoy et al. (2015) before performing soil moisture retrieval. The assimilation results are expected to be similar as a result of the similarity and consistency between the two missions. Other merged soil moisture products such as the ESA CCI soil moisture product (Dorigo et al. 2015, 2017) could combine the advantages of active and passive sensors and provide soil moisture data that are consistent in a long period with even higher temporal frequency (approximately daily), which is expected to further improve soil moisture estimates with this methodology.

One limitation of this study is the small domain and relatively short study period. In particular, the limited soil moisture heterogeneity and relatively uniform land 
cover type may reduce the added value of assimilating high-resolution soil moisture data. The impact of complex terrain and mixed land cover types should be further explored. Future studies should also evaluate the performance of the methodology at larger scales for a longer period and under different climate and soil wetness conditions, which may have an influence on the soil wetness control strength on surface energy partitioning.

Acknowledgments. The first author was financially supported for his Ph.D. research by the China Scholarship Council (CSC) (Ref. 201306040112).

\section{REFERENCES}

Abdolghafoorian, A., L. Farhadi, S. M. Bateni, S. Margulis, and T. Xu, 2017: Characterizing the effect of vegetation dynamics on the bulk heat transfer coefficient to improve variational estimation of surface turbulent fluxes. J. Hydrometeor., 18, 321-333, https://doi.org/10.1175/JHM-D-16-0097.1.

Andrews, T., P. M. Forster, and J. M. Gregory, 2009: A surface energy perspective on climate change. J. Climate, 22, 25572570, https://doi.org/10.1175/2008JCLI2759.1.

Baldocchi, D., and Coauthors, 2001: FLUXNET: A new tool to study the temporal and spatial variability of ecosystem-scale carbon dioxide, water vapor, and energy flux densities. Bull. Amer. Meteor. Soc., 82, 2415-2434, https://doi.org/10.1175/ 1520-0477(2001)082<2415:FANTTS >2.3.CO;2.

Bartalis, Z., W. Wagner, V. Naeimi, S. Hasenauer, K. Scipal, H. Bonekamp, J. Figa, and C. Anderson, 2007: Initial soil moisture retrievals from the METOP-A Advanced Scatterometer (ASCAT). Geophys. Res. Lett., 34, L20401, https:// doi.org/10.1029/2007GL031088.

Bastiaanssen, W. G., M. Menenti, R. Feddes, and A. Holtslag, 1998: A remote sensing surface energy balance algorithm for land (SEBAL). 1. formulation. J. Hydrol., 212-213, 198-212, https://doi.org/10.1016/S0022-1694(98)00253-4.

Bateni, S., and D. Entekhabi, 2012a: Relative efficiency of land surface energy balance components. Water Resour. Res., 48, W04510, https://doi.org/10.1029/2011WR011357.

, and — 2012b: Surface heat flux estimation with the ensemble Kalman smoother: Joint estimation of state and parameters. Water Resour. Res., 48, W08521, https://doi.org/10.1029/2011WR011542. , and S. Liang, 2012: Estimating surface energy fluxes using a dual-source data assimilation approach adjoined to the heat diffusion equation. J. Geophys. Res., 117, D17118, https:// doi.org/10.1029/2012JD017618.

-, D. Entekhabi, and D.-S. Jeng, 2013: Variational assimilation of land surface temperature and the estimation of surface energy balance components. J. Hydrol., 481, 143-156, https:// doi.org/10.1016/j.jhydrol.2012.12.039.

$\ldots, \ldots$, S. Margulis, F. Castelli, and L. Kergoat, 2014: Coupled estimation of surface heat fluxes and vegetation dynamics from remotely sensed land surface temperature and fraction of photosynthetically active radiation. Water Resour. Res., 50, 8420-8440, https://doi.org/10.1002/2013WR014573.

Bauer-Marschallinger, B., and Coauthors, 2018: Toward global soil moisture monitoring with Sentinel-1: Harnessing assets and overcoming obstacles. IEEE Trans. Geosci. Remote Sens., 57, 520-539, https://doi.org/10.1109/TGRS.2018.2858004.
Bell, J. E., and Coauthors, 2013: U.S. Climate Reference Network soil moisture and temperature observations. J. Hydrometeor., 14, 977-988, https://doi.org/10.1175/JHM-D-12-0146.1.

Boni, G., D. Entekhabi, and F. Castelli, 2001: Land data assimilation with satellite measurements for the estimation of surface energy balance components and surface control on evaporation. Water Resour. Res., 37, 1713-1722, https:// doi.org/10.1029/2001WR900020.

Brocca, L., and Coauthors, 2017: A review of the applications of ASCAT soil moisture products. IEEE J. Sel. Top. Appl. Earth Obs. Remote Sens., 10, 2285-2306, https://doi.org/10.1109/ JSTARS.2017.2651140.

Cai, X., and Coauthors, 2017: Validation of SMAP soil moisture for the SMAPVEX15 field campaign using a hyper-resolution model. Water Resour. Res., 53, 3013-3028, https://doi.org/ 10.1002/2016WR019967.

Caparrini, F., F. Castelli, and D. Entekhabi, 2003: Mapping of land-atmosphere heat fluxes and surface parameters with remote sensing data. Bound.-Layer Meteor., 107, 605-633, https://doi.org/10.1023/A:1022821718791.

$\longrightarrow,-$, and $-2004 \mathrm{a}$ : Estimation of surface turbulent fluxes through assimilation of radiometric surface temperature sequences. J. Hydrometeor., 5, 145-159, https://doi.org/10.1175/ 1525-7541(2004)005<0145:EOSTFT > 2.0.CO;2.

, — - and — 2004b: Variational estimation of soil and vegetation turbulent transfer and heat flux parameters from sequences of multisensor imagery. Water Resour. Res., 40, W12515, https://doi.org/10.1029/2004WR003358.

Castelli, F., D. Entekhabi, and E. Caporali, 1999: Estimation of surface heat flux and an index of soil moisture using adjointstate surface energy balance. Water Resour. Res., 35, 31153125, https://doi.org/10.1029/1999WR900140.

Chan, S. K., and Coauthors, 2016: Assessment of the SMAP passive soil moisture product. IEEE Trans. Geosci. Remote Sens., $\mathbf{5 4}$ 4994-5007, https://doi.org/10.1109/TGRS.2016.2561938.

— , and Coauthors, 2018: Development and assessment of the SMAP enhanced passive soil moisture product. Remote Sens. Environ., 204, 931-941, https://doi.org/10.1016/j.rse.2017.08.025.

Choudhury, B., S. Idso, and R. Reginato, 1987: Analysis of an empirical model for soil heat flux under a growing wheat crop for estimating evaporation by an infrared-temperature based energy balance equation. Agric. For. Meteor., 39, 283-297, https://doi.org/10.1016/0168-1923(87)90021-9.

Colliander, A., and Coauthors, 2017: Validation of SMAP surface soil moisture products with core validation sites. Remote Sens. Environ., 191, 215-231, https://doi.org/10.1016/ j.rse.2017.01.021.

Crago, R. D., 1996: Conservation and variability of the evaporative fraction during the daytime. J. Hydrol., 180, 173-194, https:// doi.org/10.1016/0022-1694(95)02903-6.

_ , and W. Brutsaert, 1996: Daytime evaporation and the selfpreservation of the evaporative fraction and the Bowen ratio. J. Hydrol., 178, 241-255, https://doi.org/10.1016/0022-1694(95) 02803-X.

Crow, W. T., and W. P. Kustas, 2005: Utility of assimilating surface radiometric temperature observations for evaporative fraction and heat transfer coefficient retrieval. Bound.-Layer Meteor., 115, 105-130, https://doi.org/10.1007/s10546-004-2121-0.

Das, N., 2013: SMAP ancillary data report: Soil attributes. SMAP Science Doc. 044, JPL D-53058, 16 pp., http://smap.jpl.nasa.gov/ files/smap2/044_soil_attrib.pdf.

De Lannoy, G. J., and R. H. Reichle, 2016: Assimilation of SMOS brightness temperatures or soil moisture retrievals into a land 
surface model. Hydrol. Earth Syst. Sci., 20, 4895, https://doi.org/ 10.5194/hess-20-4895-2016.

- _ - — - J. Peng, Y. Kerr, R. Castro, E. J. Kim, and Q. Liu, 2015: Converting between SMOS and SMAP level-1 brightness temperature observations over nonfrozen land. IEEE Geosci. Remote Sens. Lett., 12, 1908-1912, https:// doi.org/10.1109/LGRS.2015.2437612.

Dirmeyer, P. A., F. J. Zeng, A. Ducharne, J. C. Morrill, and R. D. Koster, 2000: The sensitivity of surface fluxes to soil water content in three land surface schemes. J. Hydrometeor., 1, 121-134, https://doi.org/10.1175/1525-7541(2000)001<0121: TSOSFT $>2.0 . \mathrm{CO} ; 2$.

Dong, J., S. C. Steele-Dunne, T. E. Ochsner, and N. van de Giesen, 2016: Estimating soil moisture and soil thermal and hydraulic properties by assimilating soil temperatures using a particle batch smoother. Adv. Water Resour., 91, 104116, https://doi.org/10.1016/j.advwatres.2016.03.008.

Dorigo, W., and Coauthors, 2011: The International Soil Moisture Network: A data hosting facility for global in situ soil moisture measurements. Hydrol. Earth Syst. Sci., 15, 1675-1698, https:// doi.org/10.5194/hess-15-1675-2011.

_- , and Coauthors, 2015: Evaluation of the ESA CCI soil moisture product using ground-based observations. Remote Sens. Environ., 162, 380-395, https://doi.org/10.1016/ j.rse.2014.07.023.

— - and Coauthors, 2017: ESA CCI soil moisture for improved earth system understanding: State-of-the art and future directions. Remote Sens. Environ., 203, 185-215, https://doi.org/ 10.1016/j.rse.2017.07.001.

Dunne, S., and D. Entekhabi, 2006: Land surface state and flux estimation using the ensemble Kalman smoother during the Southern Great Plains 1997 field experiment. Water Resour. Res., 42, W01407, https://doi.org/10.1029/2005WR004334.

Entekhabi, D., and Coauthors, 2010: The Soil Moisture Active Passive (SMAP) mission. Proc. IEEE, 98, 704-716, https:// doi.org/10.1109/JPROC.2010.2043918.

_ - and Coauthors, 2014: SMAP Handbook Soil Moisture Active Passive: Mapping Soil Moisture and Freeze/Thaw from Space. JPL CL14-2285, Jet Propulsion Laboratory, 180 pp., https:/ smap.jpl.nasa.gov/files/smap2/SMAP_Handbook_FINAL_1_ JULY_2014_Web.pdf.

Farhadi, L., D. Entekhabi, G. Salvucci, and J. Sun, 2014: Estimation of land surface water and energy balance parameters using conditional sampling of surface states. Water Resour. Res., 50, 1805-1822, https://doi.org/10.1002/2013WR014049.

Fernandez-Moran, R., and Coauthors, 2017: SMOS-IC: An alternative SMOS soil moisture and vegetation optical depth product. Remote Sens., 9, 457, https://doi.org/10.3390/ rs9050457.

Freitas, S. C., I. F. Trigo, J. Macedo, C. Barroso, R. Silva, and R. Perdigão, 2013: Land surface temperature from multiple geostationary satellites. Int. J. Remote Sens., 34, 3051-3068, https://doi.org/10.1080/01431161.2012.716925.

French, A. N., T. J. Schmugge, W. P. Kustas, K. L. Brubaker, and J. Prueger, 2003: Surface energy fluxes over El Reno, Oklahoma, using high-resolution remotely sensed data. Water Resour. Res., 39, 1164, https://doi.org/10.1029/2002WR001734.

Gentine, P., D. Entekhabi, A. Chehbouni, G. Boulet, and B. Duchemin, 2007: Analysis of evaporative fraction diurnal behaviour. Agric. For. Meteor., 143, 13-29, https://doi.org/ 10.1016/j.agrformet.2006.11.002.

He, X., and Coauthors, 2018: Evaluation of the weak constraint data assimilation approach for estimating turbulent heat fluxes at six sites. Remote Sens., 10, 1994, https://doi.org/10.3390/ rs10121994.

Hou, A. Y., and Coauthors, 2014: The Global Precipitation Measurement mission. Bull. Amer. Meteor. Soc., 95, 701-722, https://doi.org/10.1175/BAMS-D-13-00164.1.

Huang, C., Y. Li, J. Gu, L. Lu, and X. Li, 2015: Improving estimation of evapotranspiration under water-limited conditions based on SEBS and MODIS data in arid regions. Remote Sens., 7, 16 795-16814, https://doi.org/10.3390/rs71215854.

Huffman, G. J., D. T. Bolvin, and E. J. Nelkin, 2015: Integrated Multi-satellitE Retrievals for GPM (IMERG) technical documentation. NASA/GSFC Code 612 Tech. Doc., 48 pp., http://pmm.nasa.gov/sites/default/files/document_files/ IMERG_doc.pdf.

Imaoka, K., and Coauthors, 2010: Global Change Observation Mission (GCOM) for monitoring carbon, water cycles, and climate change. Proc. IEEE, 98, 717-734, https://doi.org/ 10.1109/JPROC.2009.2036869.

Jung, M., and Coauthors, 2011: Global patterns of land-atmosphere fluxes of carbon dioxide, latent heat, and sensible heat derived from eddy covariance, satellite, and meteorological observations. J. Geophys. Res., 116, G00J07, https://doi.org/10.1029/ 2010JG001566.

Kerr, Y. H., P. Waldteufel, J.-P. Wigneron, J. Martinuzzi, J. Font, and M. Berger, 2001: Soil moisture retrieval from space: The Soil Moisture and Ocean Salinity (SMOS) mission. IEEE Trans. Geosci. Remote Sens., 39, 1729-1735, https://doi.org/ 10.1109/36.942551.

Kilic, A., R. Allen, R. Trezza, I. Ratcliffe, B. Kamble, C. Robison, and D. Ozturk, 2016: Sensitivity of evapotranspiration retrievals from the METRIC processing algorithm to improved radiometric resolution of Landsat 8 thermal data and to calibration bias in Landsat 7 and 8 surface temperature. Remote Sens. Environ., 185, 198-209, https://doi.org/10.1016/ j.rse.2016.07.011.

Knyazikhin, Y., and Coauthors, 1999: MODIS leaf area index (LAI) and fraction of photosynthetically active radiation absorbed by vegetation (FPAR) product (MOD15). Algorithm Theoretical Basis Doc., NASA, 130 pp., https://modis.gsfc.nasa.gov/data/ atbd/atbd_mod15.pdf.

Kumar, S., T. Holmes, D. M. Mocko, S. Wang, and C. PetersLidard, 2018: Attribution of flux partitioning variations between land surface models over the continental us. Remote Sens., 10, 751, https://doi.org/10.3390/rs10050751.

Kustas, W., K. Humes, J. Norman, and M. Moran, 1996: Single-and dual-source modeling of surface energy fluxes with radiometric surface temperature. J. Appl. Meteor., 35, 110-121, https:// doi.org/10.1175/1520-0450(1996)035<0110:SADSMO > 2.0. $\mathrm{CO} ; 2$.

Lievens, H., and N. E. Verhoest, 2011: On the retrieval of soil moisture in wheat fields from L-band SAR based on water cloud modeling, the IEM, and effective roughness parameters. IEEE Geosci. Remote Sens. Lett., 8, 740-744, https://doi.org/ 10.1109/LGRS.2011.2106109.

Lu, Y., J. Dong, S. C. Steele-Dunne, and N. van de Giesen, 2016: Estimating surface turbulent heat fluxes from land surface temperature and soil moisture observations using the particle batch smoother. Water Resour. Res., 52, 90869108, https://doi.org/10.1002/2016WR018943.

- S. C. Steele-Dunne, L. Farhadi, and N. van de Giesen, 2017: Mapping surface heat fluxes by assimilating SMAP soil moisture and GOES land surface temperature data. Water Resour. Res., 53, 10 858-10 877, https://doi.org/10.1002/2017WR021415. 
Luo, L., and Coauthors, 2003: Validation of the North American Land Data Assimilation System (NLDAS) retrospective forcing over the Southern Great Plains. J. Geophys. Res., 108, 8843, https://doi.org/10.1029/2002JD003246.

Malenovský, Z., H. Rott, J. Cihlar, M. E. Schaepman, G. García-Santos, R. Fernandes, and M. Berger, 2012: Sentinels for science: Potential of Sentinel-1,-2, and-3 missions for scientific observations of ocean, cryosphere, and land. Remote Sens. Environ., 120, 91-101, https://doi.org/ 10.1016/j.rse.2011.09.026.

McCabe, M. F., and E. F. Wood, 2006: Scale influences on the remote estimation of evapotranspiration using multiple satellite sensors. Remote Sens. Environ., 105, 271-285, https://doi.org/ 10.1016/j.rse.2006.07.006.

Njoku, E. G., T. J. Jackson, V. Lakshmi, T. K. Chan, and S. V. Nghiem, 2003: Soil moisture retrieval from AMSR-E. IEEE Trans. Geosci. Remote Sens., 41, 215-229, https://doi.org/ 10.1109/TGRS.2002.808243.

Norman, J. M., W. P. Kustas, and K. S. Humes, 1995: A two-source approach for estimating soil and vegetation energy fluxes in observations of directional radiometric surface temperature. Agric. For. Meteor., 77, 263-293, https://doi.org/10.1016/0168-1923(95) 02265-Y.

Paloscia, S., S. Pettinato, E. Santi, C. Notarnicola, L. Pasolli, and A. Reppucci, 2013: Soil moisture mapping using Sentinel-1 images: Algorithm and preliminary validation. Remote Sens. Environ., 134, 234-248, https://doi.org/10.1016/j.rse.2013.02.027.

Peng, J., M. Borsche, Y. Liu, and A. Loew, 2013: How representative are instantaneous evaporative fraction measurements for daytime fluxes? Hydrol. Earth Syst. Sci., 17, 3913-3919, https://doi.org/10.5194/hess-17-3913-2013.

Petropoulos, G. P., G. Ireland, and B. Barrett, 2015: Surface soil moisture retrievals from remote sensing: Current status, products \& future trends. Phys. Chem. Earth, 83-84, 36-56, https://doi.org/10.1016/j.pce.2015.02.009.

Rigden, A. J., and G. D. Salvucci, 2015: Evapotranspiration based on equilibrated relative humidity (ETRHEQ): Evaluation over the continental U.S. Water Resour. Res., 51, 2951-2973, https://doi.org/10.1002/2014WR016072.

Sadeghi, M., E. Babaeian, M. Tuller, and S. B. Jones, 2017: The optical trapezoid model: A novel approach to remote sensing of soil moisture applied to Sentinel-2 and Landsat- 8 observations. Remote Sens. Environ., 198, 52-68, https://doi.org/ 10.1016/j.rse.2017.05.041.

Schaap, M. G., F. J. Leij, and M. T. Van Genuchten, 2001: ROSETTA: A computer program for estimating soil hydraulic parameters with hierarchical pedotransfer functions. J. Hydrol., 251, 163-176, https://doi.org/10.1016/S0022-1694(01)00466-8.

Schaefer, G. L., M. H. Cosh, and T. J. Jackson, 2007: The USDA natural resources conservation service Soil Climate Analysis Network (SCAN). J. Atmos. Oceanic Technol., 24, 2073-2077, https://doi.org/10.1175/2007JTECHA930.1.

Sini, F., G. Boni, F. Caparrini, and D. Entekhabi, 2008: Estimation of large-scale evaporation fields based on assimilation of remotely sensed land temperature. Water Resour. Res., 44, W06410, https://doi.org/10.1029/2006WR005574.

Su, Z., 2002: The Surface Energy Balance System (SEBS) for estimation of turbulent heat fluxes. Hydrol. Earth Syst. Sci., 6, 85-100, https://doi.org/10.5194/hess-6-85-2002.

Tang, R., Z.-L. Li, and B. Tang, 2010: An application of the $\mathrm{T}_{s}-\mathrm{VI}$ triangle method with enhanced edges determination for evapotranspiration estimation from MODIS data in arid and semi-arid regions: Implementation and validation. Remote Sens. Environ., 114, 540-551, https://doi.org/10.1016/ j.rse.2009.10.012.

Vinukollu, R. K., E. F. Wood, C. R. Ferguson, and J. B. Fisher, 2011: Global estimates of evapotranspiration for climate studies using multi-sensor remote sensing data: Evaluation of three process-based approaches. Remote Sens. Environ., 115, 801-823, https://doi.org/10.1016/j.rse.2010.11.006.

Xia, Y., and Coauthors, 2012: Continental-scale water and energy flux analysis and validation for the North American Land Data Assimilation System project phase 2 (NLDAS-2): 1. Intercomparison and application of model products. J. Geophys. Res., 117, D03109, https://doi.org/10.1029/ 2011JD016048.

Xu, T., S. Bateni, S. Liang, D. Entekhabi, and K. Mao, 2014 Estimation of surface turbulent heat fluxes via variational assimilation of sequences of land surface temperatures from Geostationary Operational Environmental Satellites. J. Geophys. Res. Atmos., 119, 10 780-10 798, https://doi.org/ 10.1002/2014JD021814.

- S. M. Bateni, and S. Liang, 2015: Estimating turbulent heat fluxes with a weak-constraint data assimilation scheme: A case study (hiWATER-MUSOEXE). IEEE Geosci. Remote Sens. Lett., 12, 68-72, https://doi.org/10.1109/LGRS.2014.2326180.

, — , S. A. Margulis, L. Song, S. Liu, and Z. Xu, 2016: Partitioning evapotranspiration into soil evaporation and canopy transpiration via a two-source variational data assimilation system. J. Hydrometeor., 17, 2353-2370, https://doi.org/10.1175/ JHM-D-15-0178.1.

$\longrightarrow$, S. Bateni, C. Neale, T. Auligne, and S. Liu, 2018: Estimation of turbulent heat fluxes by assimilation of land surface temperature observations from GOES satellites into an ensemble Kalman smoother framework. J. Geophys. Res. Atmos., 123, 2409-2423, https://doi.org/10.1002/2017JD027732.

, X. He, S. M. Bateni, T. Auligne, S. Liu, Z. Xu, J. Zhou, and K. Mao, 2019: Mapping regional turbulent heat fluxes via variational assimilation of land surface temperature data from polar orbiting satellites. Remote Sens. Environ., 221, 444-461, https://doi.org/10.1016/j.rse.2018.11.023.

Yang, Y., H. Su, R. Zhang, J. Tian, and L. Li, 2015: An enhanced two-source evapotranspiration model for land (ETEML): Algorithm and evaluation. Remote Sens. Environ., 168, 54-65, https://doi.org/10.1016/j.rse.2015.06.020.

, J. Qiu, R. Zhang, S. Huang, S. Chen, H. Wang, J. Luo, and Y. Fan, 2018: Intercomparison of three two-source energy balance models for partitioning evaporation and transpiration in semiarid climates. Remote Sens., 10, 1149, https://doi.org/ 10.3390/rs10071149.

Zhang, D., R. Tang, B.-H. Tang, H. Wu, and Z.-L. Li, 2015: A simple method for soil moisture determination from LSTVI feature space using nonlinear interpolation based on thermal infrared remotely sensed data. IEEE J. Sel. Top. Appl. Earth Obs. Remote Sens., 8, 638-648, https://doi.org/ 10.1109/JSTARS.2014.2371135.

Zhao, W., A. Li, H. Jin, Z. Zhang, J. Bian, and G. Yin, 2017: Performance evaluation of the triangle-based empirical soil moisture relationship models based on Landsat-5 TM data and in situ measurements. IEEE Trans. Geosci. Remote Sens., 55, 2632-2645, https://doi.org/10.1109/TGRS.2017.2649522. 